\title{
Diagnosis and therapy of neuroendocrine neoplasms of the gastrointestinal tract
}

\author{
ANDRZEJ DEPTAłA ${ }^{1,2, \text { A-F }}$, ALEKSANDRA IZABELA CZERW'3, E, F
}

${ }^{1}$ Department of Oncology and Hematology, Central Clinical Hospital of the Ministry of the Interior,

Warsaw

${ }^{2}$ Department of Cancer Prevention, Medical University of Warsaw

${ }^{3}$ Department of Public Health, Medical University of Warsaw

A - Study Design, B - Data Collection, C - Statistical Analysis, D - Data Interpretation, E - Manuscript Preparation,

$\mathbf{F}$ - Literature Search, $\mathbf{G}$ - Funds Collection

Summary A neuroendocrine neoplasm (NEN) is a tumor that originates in neuroendocrine cells capable of producing peptides or amines. Neuroendocrine neoplasms of the digestive system are also referred to as gastroenteropancreatic neuroendocrine neoplasms (GEP NEN) and constitute a heterogeneous group of growths originating from at least 15 types of specialized cells spread throughout the stomach, small intestine, large intestine, and pancreas. Some GEP NENs have a secretory capacity and are referred to as hormonally active NENs. However, the majority of GEP NENs are hormonally inactive. GEP NENs are relatively rare neoplasms (around $2 \%$ of the overall number of neoplasms of the digestive system) with an incidence of around 6 cases per 100,000 per year. In the diagnosing NENs, imaging methods based on morphology (such as USG, EUS, CT, MRI, and endoscopy) and functional techniques (like somatostatin receptor scintigraphy and gallium isotope PET-CT) are applied. The type of treatment for NEN is determined by the degree of malignancy, stage, somatostatin receptor expression, symptoms of hypersecretion syndrome, general health of patient, and presence of concomitant diseases. Therapeutic approaches to GEP-NEN include combinations of the following methods: surgery, ablation techniques, somatostatin receptor-based therapy (nonconjugated analogues of somatostatin - "cold" SSTA; and analogues conjugated with a radioactive isotope of yttrium $\left({ }^{90} \mathrm{Y}\right.$ ) or lutetium $\left({ }^{177} \mathrm{Lu}\right)$ - "hot" SSTA), chemotherapy, and molecular targeted therapy (everolimus, sunitinib).

Key words: neuroendocrine neoplasm, overview, symptoms, diagnosis, treatment.

\section{Nomenclature, etiopathogenesis, and classification}

(NENs) are tumors that originate in neuroendocrine cells capable of producing peptides or amines. Neuroendocrine cells can be found in strictly endocrine tissue (such as the pituitary gland, parathyroid gland, or adrenal gland) or in de facto glandular tissue (such as the thyroid, pancreas, prostate, and ovaries), or they might be spread throughout the tissues of the digestive or respiratory system.

Neuroendocrine neoplasms of the digestive system are also referred to as gastroenteropancreatic neuroendocrine neoplasms (GEP NEN) and constitute a heterogeneous group of growths originating from at least 15 types of specialized cells spread throughout the stomach, small intestine, large intestine, and pancreas. Some GEP NENs have secretory capacity and are referred to as hormonally active NENs. The clinical symptoms are contingent on the secreted substance. The majority of GEP NENs do not secrete enough peptides and biogenic amines to evoke any clinical symptoms. Those are referred to as hormonally inactive NENs.

Most GEP NENs develop sporadically as a result of somatic mutations of MEN1 gene, genes responsible for the remodeling of chromatin (e.g. DAXX, ATRX), mTOR genes (the mammalian target of rapamycin) - such as PTEN (phosphatase and tensin homolog), PIK3CA (phosphatidylinositol-4,5-bisphosphate 3-kinase, catalytic subunit alpha), and TSC2 (tuberous sclerosis complex) - and genes associated with angiogenesis that control the expression of VEGF (vas- cular endothelial growth factor), PDGF (platelet-derived growth factor), and KIT (C-KIT) and VHL (usually the loss of heterozygosity $(\mathrm{LOH})$ type).

There is a small group of inherited GEP NENs that usually develop as a part of inherited multiple endocrine neoplasia (MEN) syndromes, which include MEN1 syndrome, Von Hippel-Lindau disease (VHL), and type-1 neurofibromatosis. All these syndromes are inherited according to the autosomal dominant inheritance pattern.

The MEN1 syndrome (Wermer's syndrome) encompasses pancreatic NEN (also called pancreatic neuroendocrine tumors (pNET); these are $80-100 \%$ gastrinomas, $50 \%$ insulinomas, 20\% somatostatinomas, with other forms rare), adenomas (or hyperplasia) of the parathyroid glands, and adenomas of the pituitary gland (usually prolactinoma). MEN1 syndrome is caused by the germinal mutation of the MEN1 suppressor gene.

Von Hippel-Lindau disease (VHL) results from germinal mutation of VHL suppressor gene and predisposes to a number of various benign and malignant tumors that assume various clinical forms: embryonic hemangioma in the pituitary gland, true cysts and renal cystadenomas, clear cell renal cell carcinoma, pheochromocytoma, paraganglioma, true cysts in the pancreas, endolymphatic sac tumor, papilloma of the epididymis, a cyst of the broad ligament of the uterus, and pancreatic NEN (pNET).

Neurofibromatosis type 1 (von Recklinghausen disease) results from a mutation of NF-1 suppressor gene. The disorder is characterized by café au lait spots on the skin, neurofibromas of the skin and plexuses, optic nerve gliomas, mal- 
formations within the skeletal system and soft tissue, bone sarcomas, Wilms' tumors, and somatostatinoma GEP NEN.

The histopathological diagnosis of NEN requires identification of the expression of synaptophysin and chromogranin A in neoplastic cells by means of immunohistochemistry. In terms of histopathology, NENs are characterized by a high degree of cellular diversity (G1, G2, or G3), which is usually assessed by immunohistochemical staining with a monoclonal antibody that identifies antigen Ki-67 (proliferation marker). Thus, NENs can be classified into the following subtypes: G1 ( $\mathrm{Ki}-67<3 \%), \mathrm{G} 2$ ( $\mathrm{Ki}-67$ in the range 3-20\%), G3 (Ki-67 > 20\%). Nonetheless, from the clinical point of view, a fundamental indicator of malignancy of NEN is the presence of metastases which occur irrespective of G level, although the frequency varies (being most common in G3 and least common in G1).

The current classification of NENs, according to the 2010 WHO classification, describes five types of NEN:

1) G1 neuroendocrine neoplasm/tumor (carcinoid): NEN/NET G1;

2) G2 neuroendocrine neoplasm/tumor: NEN/NET G2;

3) neuroendocrine carcinoma, large cell or small cell type: NEC (in former classifications called NET G3);

4) mixed adenoneuroendocrine carcinoma: MANEC; and

5) hyperplastic and preneoplastic lesions.

However, the literature and everyday medical practice still rely on terms such as the following to describe NENs: islet cell tumor (pancreatic neuroendocrine neoplasm), carcinoid, pNET (pancreatic neuroendocrine tumor $=$ islet cell carcinoma $=$ pancreatic carcinoid), insulinoma, glucagonoma, gastrinoma, etc. The names originate from the past and were coined by various scientific associations (ENETS, $\mathrm{AJCC}, \mathrm{WHO}$ ).

The current European Neuroendocrine Tumour Society (ENETS) definition of carcinoid states that it is a midgut NEN G1/NEN G2 that secretes serotonin.

The archenteron (or primary gut - a structure that forms during gastrulation and develops into the digestive tract) is composed of a foregut, a midgut and a hindgut.

- The foregut develops into the airways, the lower section of the esophagus, the stomach, the proximal half of the duodenum, the bile duct, liver, and pancreas.

- The midgut develops into the distal half of the duodenum, the small intestine, the appendix, the ascending colon, and the proximal two thirds of the transverse colon.

- The hindgut develops into the distal third of the transverse colon, the descending colon, the sigmoid colon, and the rectum.

Using the above nomenclature, one can refer to bronchial carcinoid as well as islet cell adenoma as foregut neuroendocrine tumors.

In the present text, we will use the nomenclature consistent with WHO 2010 classification and, for hormonally active tumors, the proper names, e.g. insulinoma.

\section{Epidemiology}

GEP NENs are relatively rare neoplasms (accounting for around $2 \%$ of the overall number of neoplasms of the digestive system) with an incidence of around 6 cases per 100,000 per year. Between 1973 and 2004, the prevalence of GEP NEN increased from 2.1 to 5.25 new cases per 100,000 per year. The most common location of the primary tumor is the small intestine $(37.4 \%)$. Based on an epidemiologic study conducted in the USA and Norway, the incidence of NEN of the stomach and rectum was found to have increased at the cost of incidence of NEN of the appendix.
Around $50 \%$ of GEP NENs are midgut tumors, usually carcinoids of the small intestine (23-38\%) that are identified by chance during surgery on the small intestine or appendix, or upon discovery of carcinoid syndrome. The next group of common GEP NENs are pancreatic NENs (around 30\%) followed by neuroendocrine tumors of the rectum (around $14 \%$ ) and the colon (around 8\%).

\section{Clinical presentation}

Patients with GEP NEN have different subjective and objective symptoms depending on the volume and location of the tumor and the substance secreted by the neoplasm. The most common symptom associated with the presence of GEP NEN is nonspecific abdominal pain caused by slow local growth of the tumor, which often leads to subobstruction or obstruction of the digestive tract. An exceptionally rare symptom is obstructive jaundice caused by NEN located in the head of the pancreas. The tumors usually develop in the body or tail of the pancreas, and if they are hormonally inactive, they sometimes show no symptoms for many years. A large tumor in the body or tail of the pancreas may cause pain radiating to the back or shoulder blade.

Nonsecretory GEP NEN only rarely causes symptoms characteristic of adenocarcinomas of the digestive system, such as constipation and diarrhea, bleeding in the digestive tract, weight loss, and cachexia. Patients with advanced nonsecretory GEP NENs usually enjoy surprisingly good general health. If the GEP NEN is diagnosed at the phase of dissemination to the liver, lymph nodes, lungs or bones, the prevailing symptoms arise from the metastatic lesions.

The majority of GEP NENs are nonsecretory tumors. Around $40 \%$ of GEP NENs are hormonally active tumors, which manifests in the secretion of biogenic amines, hormones, and various peptides. In such cases, the clinical symptoms depend on the type of substance secreted by neoplastic cells. These are usually symptoms of carcinoid syndrome contingent on the secretion of serotonin. A description of the most common secretory GEP NENs follows.

\section{Carcinoid}

Carcinoid is the most common type of neuroendocrine neoplasm. It usually develops in the digestive tract, within the appendix ( $40 \%$ of cases), the ileum ( $27 \%$ of cases), or the rectum (14\% of cases). It also occurs in the bronchi (in around $25 \%$ of cases). Within the digestive tract, carcinoids are midgut neoplasms that secrete serotonin. Although a carcinoid is a slowly growing neoplasm that secretes serotonin, it also secretes chromogranin $\mathrm{A}(\mathrm{CgA})$, which is considered the most useful indicator for monitoring all GEP NENs, irrespective of the limitations associated with the determination of the protein.

The diagnosis of carcinoid is often made accidentally, following surgery performed for a different reason. The symptoms are determined by the location of the neoplasm - for example, within the appendix, it leads to narrowing of the lumen and acute inflammation; within the small intestine, it causes subobstruction or obstruction of the digestive tract; in the rectum, it leads to bleeding. When metastases are present in the liver, the hypersecretion of serotonin causes so-called carcinoid syndrome, which encompasses the following array of symptoms: flushing of the face and neck, tachycardia, vertigo, hyperhidrosis, bronchoconstriction, and heart valve insufficiency as a result of fibrotic lesions of the endocardium on the right side of the heart caused by serotonin. The symptoms can also include diarrhea, weight loss, and pellagra-like skin lesions. The diagnosis of carcinoid syndrome is aided by determining the level of 5-hydroxyindoleacetic acid (5-HIAA) in two urine samples collected within the same day. 


\begin{tabular}{|c|c|c|c|c|c|}
\hline PTHrPoma & VIPoma & PPoma & ACTHoma & Somatostatinoma & GRFoma \\
\hline $\begin{array}{l}\text { Hypercalcemia } \\
\text { Bone destruction } \\
\text { Renal calculus } \\
\text { Ulcer disease }\end{array}$ & $\begin{array}{l}\text { Diarrhea } \\
\text { Dehydration } \\
\text { Weight loss } \\
\text { Spasmodic ab- } \\
\text { dominal pain } \\
\text { Hypokalemia } \\
\text { Achlorhydria }\end{array}$ & $\begin{array}{l}\text { Usually no symp- } \\
\text { toms; } \\
\text { Itching erythema- } \\
\text { tous papular rash } \\
\text { identified }\end{array}$ & $\begin{array}{l}\text { Cushing's syn- } \\
\text { drome }\end{array}$ & $\begin{array}{l}\text { Gallstone } \\
\text { Mild diabetes } \\
\text { Steatorrhea }\end{array}$ & Acromegaly \\
\hline
\end{tabular}

PTHrP - parathyroid hormone-related peptide; GRF - growth hormone-releasing factor.

The diagnosis may be confirmed by verifying the concentration of serotonin in blood serum and the concentration of chromogranin A (CgA).

\section{Insulinoma}

Insulinoma is the most common pancreatic NEN that is hormonally active. Malignant tumors account for less than $10 \%$ of the cases. The clinical symptoms are a consequence of hypoglycemia, and not of the presence of the tumor, whose diameter usually does not exceed $2 \mathrm{~cm}$. The usual symptoms of neuroglycopenia include headache and vertigo, blurred vision, double vision, concentration problems, sleepiness, delusions, and convulsions. Hypoglycemia develops a few hours after food consumption and can be provoked by physical exercise, alcohol consumption, or a low-calorie diet. Whipple's triad can prove useful in the diagnosis of insulinoma:

1) clinical symptoms that suggest hypoglycemia,

2) a documented decrease in glucose concentration below $40 \mathrm{mg} / \mathrm{dl}(2.2 \mathrm{mmol} / \mathrm{l})$ at the time of the symptoms,

3) relief of symptoms after consumption of carbohydrates.

Aside from measured hypoglycemia, precise biochemical tests aim to identify disproportionally high concentration of insulin $\geq 6 \mathrm{mU} / \mathrm{l}(\geq 36 \mathrm{pmol} / \mathrm{l})$, C-peptide $\geq 200 \mathrm{pmol} / \mathrm{l}$, and proinsulin $\geq 5 \mathrm{pmol} / \mathrm{l}$. A 72 -hour or 48 -hour fasting test is performed to confirm the diagnosis, where the hypoglycemia usually develops in the course of the first 18-24 hours of fasting.

\section{Gastrinoma}

A gastrinoma is a GEP NEN typically located within the duodenum $(70 \%)$; it is less often found in the pancreas $(20 \%)$ and other organs (5\%) (stomach, liver, ovaries, and lungs). The tumor secretes gastrin, which leads to excessive production of gastric acid. The most common symptoms of the neoplasm include persistent pain in the epigastrium, nausea, vomiting, diarrhea that disappears after administration of proton-pump inhibitors, weight loss, and bleeding from the digestive tract.

Gastrinoma causes Zollinger-Ellison syndrome (ZES), which manifests in recurrent ulceration of the stomach and duodenum, acute inflammation of the esophagus, and diarrhea. Other features of ZES include ulceration of the upper section of the digestive tract with atypical location, characterized by resistance to treatment and recurrence, with negative results for Helicobacter pylori tests and the presence of thick mucosal folds in the stomach in gastroscopy (in the case of $92 \%$ of patients with ZES). Around one third of the patients with ZES are diagnosed with MEN1 syndrome and have multiple gastrinomas in the duodenum.

Gastrinomas of the duodenum are usually small and rarely $(<10 \%)$ spread to the liver (this is more common with ZES/MEN1 than with sporadic tumors), unlike pancreatic gas- trinomas (around 30\%). Gastrinoma is diagnosed when the concentration of fasting gastrin at least 10 times greater than then norm and the stomach $\mathrm{pH}$ is $<2$. In the majority of cases, the increased concentration of gastrin is accompanied by an increased concentration of chromogranin A in blood serum.

\section{Glucagonoma}

Glucagonoma is a rare pancreatic NEN that secretes glucagon. Patients develop mild diabetes and necrolytic erythema (a pathognomic sign of glucagonoma dependent on hypoaminoacidemia) around the mouth, buttocks, and sex organs. Those characteristic symptoms may be accompanied by weight loss, diarrhea, nausea, abdominal pain, normocytic (or macrocytic) anemia, and frequent episodes of thromboembolism (30\% of patients), along with depressive episodes.

Table 1 presents the clinical symptoms resulting from the less common pancreatic NENs.

\section{Diagnostic biochemistry}

Diagnostic biochemistry of GEP NEN involves specific and nonspecific markers. The nonspecific markers usually cover the determination of chromogranin $\mathrm{A}(\mathrm{CgA})$ in blood serum. Specific markers have been described above for particular types of GEP NEN.

Chromogranin $\mathrm{A}$ is a protein produced and released into the blood by neuroendocrine cells. The concentration of chromogranin A is elevated in the majority of NENs, although the CgA levels in serum can be elevated by a large number of other factors (administration of proton-pump inhibitors and $\mathrm{H} 2$ blockers, atrophic gastritis, pancreatitis, inflammatory intestine disease, hepatitis and liver cirrhosis, rheumatoid arthritis, renal insufficiency, circulatory failure, myocardial infarction, chronic bronchopulmonary disease, neoplasms other than GEP NEN, hyperthyroidism, hyperparathyroidism, treatment with glycocorticosteroids, Parkinson's disease, physical exercise, and a heavy meal before the test). The concentration of CgA in GEP NEN serves as an independent prognostic factor for survival. The results of research indicated that the concentration of $\mathrm{CgA}$ is determined by the variation of NEN (this is lower in G3than in $\mathrm{G} 1 / \mathrm{G} 2$ ) and that there is a correlation between CgA concentration and the volume of the tumor, with the highest levels being found in patients with metastases in the liver.

\section{Diagnostic imaging}

Patients with NEN undergo imaging tests to identify the original tumor, to evaluate the stage of the neoplasm and its response to treatment, to qualify them for radionuclide treatment, and to monitor them if undergoing radical treatment.

The diagnostic imaging of NEN employs imaging methods based on morphology and functional techniques. Morphological scans include ultrasound, endoscopic ul- 
trasound, computed tomography, magnetic resonance imaging, endoscopy, capsule endoscopy, double-balloon enteroscopy, the choice depending on the location of the GEP NEN. The functional methods include somatostatin receptor scintigraphy (SRS, which is more efficient as a whole body scan (WB-SPECT)) - which images the expression of somatostatin receptors (SSTR) - and PET-CT with the use of somatostatin analogues conjugated with gallium isotope $\left({ }^{68} \mathrm{Ga}\right.$-DOTATATE PET-CT). The concurrent application of morphological and functional techniques allows for increased sensitivity and specificity of tests in the diagnosis of NEN, in light of the potential difficulties arising from the small size of the tumors, their atypical location, and the nonspecific clinical symptoms.

The classic ${ }^{18}$ FDG-PET-CT test is of minor significance in the diagnosis of varied GEP NENs with low proliferative index (G1), but can be useful in the diagnosis of GEP NEN G2 (when Ki-67 > 5\%), and should be applied in the evaluation of the stage of the disease and of the response to treatment in case of neuroendocrine cancers (NEC) with high proliferative index (Ki-67 > 20\%). Around $5 \%-8 \%$ of NECs exhibit the expression of SSTR. In these cases, ${ }^{18} \mathrm{FDG}$-PET-CT should be accompanied by ${ }^{68} \mathrm{Ga}$-DOTATATE PET-CT.

\section{Treatment}

The treatment for NEN is determined by malignancy (G), stage (TNM/AJCC), expression of somatostatin receptors (SSTR), symptoms of hypersecretion syndrome, the general health of patient, and presence of concomitant diseases.

In case of diagnosed GEP NEN with no distal metastases, one choice is surgical treatment, whose scope will be determined by the general health of the patient and the location, size, and nature of the tumor. Radical surgery is the only treatment option that gives a chance of a cure, which is why the treatment should be applied even in advanced cases - for instance, with resectable metastases in the liver. As with colorectal cancer, radical resection of the primary tumor and of the metastasis in the liver may lead to longterm survival.

Surgical treatment methods aimed at extending life and improving the quality of life include:

- $\quad$ palliative resection of metastases - so-called cytoreductive surgery, which is a nonradical resectioning that consists of reducing the volume of the tumor (by up to $90 \%$ ), with the aim of alleviating the symptoms of hormonal hypersecretion (for metastases in the liver);

- liver transplant, in case of disease restricted to this organ.

Other surgical methods include endoscopic resection (endoscopic mucosal resection, EMR, and endoscopic mucosal dissection, ESD). When applied to well differentiated (G1) GEP NENs of the stomach, duodenum, or rectum at an early stage (T1, according to TNM/AJCC), such methods can achieve a high rate of curability. Bile duct stenting and bypasses are palliative procedures.

Ablation techniques play a certain role in the treatment of unresectable metastatic tumors that are restricted to the liver. Such include methods such as: radiofrequency ablation (RFA), transarterial chemoembolization (TACE, using cytostatics such as doxorubicin, cisplatin, and irinotecan) and radioembolization (selective internal radiation therapy (SIRT), using microspheres conjugated with the yttrium isotope ${ }^{90} \mathrm{Y}$ ).

In systemic treatment of GEP NEN, the choice of treatment method is contingent on the stage of the neoplasm and SSTR expression. Following radical surgical treatment of GEP NEN G1 and G2, there are no indications for systemic adjuvant (adjunctive) therapy. In the case of neuroendocrine cancers (NEC), the adjuvant therapy should be aided by chemotherapy, usually based on the application of cisplatin and etoposide.

Upon examination of disseminated GEP NENs with expression of SSTR using SRS-WB-SPECT or ${ }^{68} \mathrm{Ga}$-DOTATATE PET-CT, the gold standard of systemic treatment is the nonconjugated analogues of somatostatin ("cold" SSTA), octreotide LAR, and lanreotide autogel (the other options are not available in Poland). These drugs hinder the secretion of hormones and biologically active agents and allow the disease symptoms to be controlled, thus improving the quality of life of patients. Their antiproliferative effects help block the progress of GEP NEN, irrespective of the hormonal activity of the tumor.

Aside from "cold" SSTA, the treatment of GEP NEN also relies on "hot" analogues - that is, analogues conjugated with radioactive isotopes of yttrium $\left({ }^{90} \mathrm{Y}\right)$ and lutetium $\left({ }^{177} \mathrm{Lu}\right)$ which emit beta rays (peptide receptor radionuclide therapy PRRT). Currently, a tandem method based on both isotopes is popular $\left({ }^{90} \mathrm{Y} /{ }^{177}\right.$ Lu-DOTATATE; DOTATATE = Octreotate = somatostatin analogue). Patients who qualify for isotope treatment are those with advanced nonresectable neuroendocrine neoplasms with expression of somatostatin receptors identified by SRS or gallium PET-CT. The optimum therapeutic effect - a decrease in tumor volume, alleviation of hormonal symptoms, and extension of life - is seen in patients with a strong accumulation of "hot" SSTA in all (or most) foci.

Classic systemic chemotherapy is also used in the treatment of disseminated GEP NENs. Chemotherapy, as a treatment for NEN G1 and NEN G2, is more effective in neoplasms originating from the pancreas than in those from other locations. In such cases, the treatment may be based on streptozotocin (STZ; not refunded in Poland), doxorubicin, and fluorouracil (5-FU). Recently, it has been demonstrated that a combination of temozolomide and capecitabine offers better survival than treatment based on STZ, which is why this solution is preferred by oncologists. Chemotherapy featuring cisplatin and etoposide is the basic method of palliative treatment for advanced NEC.

Irrespective of the location, patients with advanced GEP NEN G1 and G2 can benefit from the use of molecularly targeted drugs, such as everolimus (an inhibitor of serinethreonine kinase mTOR that inhibits the metabolism and proliferation of cells and, indirectly, angiogenesis) and sunitinib (multikinase inhibitor of VEGFR1-3, PDGFR $\alpha \beta$, c-KIT, FLT3, and CSF1R with antiangiogenic and antiproliferative effects) in respect of survival.

Source of funding: This work was funded by the authors' resources. Conflict of interest: The authors declare no conflict of interests.

\section{References}

1. Alexakis N, Halloran C, Raraty M, et al. Current standards of surgery for pancreatic cancer. Brit J Surg 2004; 91(11): 1410-1427.

2. Asendrych A, Deptała A. Analogi somatostatyny jako leki przeciwnowotworowe. Współcz Onkol 2003; 7(1): 32-38.

3. Bonenkamp JJ. Surgery for upper gastrointestinal malignancies. Semin Oncol 2004; 31(4): 542-553. 
4. Deptała A, Asendrych A, Omyła-Staszewska J, et al. Rola terapii systemowej w leczeniu guzów neuroendokrynnych układu pokarmowego. Prz Gastroenterol 2006; 1(1): 10-15.

5. Asendrych-Woźniak A, Deptała A. Leczenie nowotworów neuroendokrynnych układu pokarmowego za pomocą analogów somatostatyny. Contem Oncol 2013; 17(3) (Supl. 2): 13-16.

6. Deptała A, Asendrych-Woźniak A, Omyła-Staszewska J. Zastosowanie leków celowanych molekularnie w leczeniu nowotworów neuroendokrynnych układu pokarmowego. Contem Oncol 2013; 17(3) (Supl. 2): 22-26

7. DeVita VT Jr, Hellman S, Rosenberg SA, eds. Cancer. Principles \& practice of oncology. 10th ed. Philadelphia: Lippincott Williams \& Wilkins; 2015.

8. Kos-Kudła B, Blicharz-Dorniak J, Handkiewicz-Junak D, et al. Zalecenia ogólne dotyczące postępowania w nowotworach neuroendokrynnych układu pokarmowego (rekomendowane przez Polską Sieć Guzów Neuroendokrynnych) oraz rozdziały narządowe. Endokrynol Pol 2013; 64(6): 418-504

9. Kos-Kudła B, Deptała A. Rola leczenia ukierunkowanego molekularnie w nowotworach neuroendokrynnych przewodu pokarmowego i płuc. In: Wojtukiewicz M, E. Sierko E, eds. Leczenie ukierunkowane na cele molekularne w onkologii i hematologii. Gdańsk: Via Medica; 2013: 448-467.

10. Deptała A, Romanowicz A. Nowotwory neuroendokrynne układu pokarmowego. In: Deptała A, Wojtukiewicz MZ, eds. Onkologia w praktyce lekarza rodzinnego. Gdańsk: Wydawnictwo AsteriaMed 2016: 228-236.

Adress for correspondence:

Aleksandra Czerw, PhD

Zakład Zdrowia Publicznego

Wydział Nauk o Zdrowiu WUM

ul. Banacha 1a, blok F

02-097 Warszawa

Polska

Tel.: +48 501 176-370

E-mail: ola_czerw@wp.pl

Received: 23.06.2016

Revised: 24.06.2016

Accepted: 10.07.2016 